\title{
The Effect of Thai Majors' Overseas Study on Intercultural Competence: A Case Study of Thai Majors of Yunnan Agricultural University
}

\author{
Dimin Luo \\ School of Foreign Languages, Yunnan Agricultural University, Kunming, China \\ Email: luodimin@163.com
}

How to cite this paper: Luo, D. M. (2021). The Effect of Thai Majors' Overseas Study on Intercultural Competence: A Case Study of Thai Majors of Yunnan Agricultural University. Creative Education, 12, 871-879. https://doi.org/10.4236/ce.2021.124063

Received: March 23, 2021

Accepted: April 25, 2021

Published: April 28, 2021

Copyright $\odot 2021$ by author(s) and Scientific Research Publishing Inc. This work is licensed under the Creative Commons Attribution International License (CC BY 4.0).

http://creativecommons.org/licenses/by/4.0/ (c) (i) Open Access

\begin{abstract}
This study adopted both intercultural competence assessment and interview to analyze the effect of the "overseas study" learning mode on cultivating and improving students' intercultural competence. The factors that influenced the development of college students' intercultural competence were summarized. The study revealed that there were differences in the dimensions of native and Thai cultural knowledge, intercultural skills and awareness. It also demonstrated that gender, language capability and culture knowledge were responsible for the discrepancy. The study recommended that it is inevitable to strengthen culture comparison in overseas learning and strengthen female's intercultural competence.
\end{abstract}

Keywords

Intercultural Competence, Overseas Study, Thai Majors

\section{Introduction}

In the context of the continuous deepening of China-ASEAN economic and trade cooperation, our school implements the " $3+1$ " international cooperation model, providing Thai majors with an opportunity to study abroad, communicate and practice in Thailand for one year. At the same time, the overseas learning process is helpful to cultivate students' intercultural communication ability. As foreign language learners, intercultural competence is an important ability that Thai language majors must master in order to meet their needs of studying abroad, communicating and working. Improving intercultural communication competence of Thai majors has become the key to talent cultivation. However, the current domestic scholars often propose intercultural communication strategy training system and methods only based on the theoretical induction as well 
as their own observation and experience, but have failed to provide supporting data to fully demonstrate Thai majors' intercultural competence in their overseas study. To make up for this deficiency, this paper attempts to take the Thai majors of Yunnan Agricultural University, Grade 2016 and Grade 2017, as an example to explore the influence of " $3+1$ " cooperative education mode on students' intercultural competence by longitudinal comparison of their intercultural competence in nearly one year before and after overseas study.

\section{Literature Review}

\subsection{Definitions of Intercultural Competence}

During the intercultural interaction, intercultural competence is indispensable. Numerous terms and definitions regarding intercultural competence have been proposed by scholars from different countries. Kim (1991) believed that intercultural competence is an individual's ability to cope with major challenge factors in the new environment. Spitzberg (2000) pointed out that it is an appropriate and effective behavior in a specific environment. Wiseman (2003) made a point of it is the ability to effectively and appropriately complete communicative behaviors in a specific environment to obtain the expected response. Samovar et al. (2010) believed that intercultural competence is the ability of individuals to analyze the environment and choose the right behavior pattern. Myron W. Lusting and Jolene Koester (1996), American experts on communication, defined "intercultural competence" as "the ability to become effective and appropriate in interacting across cultures". It is the ability to comprehend and adjust to the target culture without neglecting the native culture. On the whole, intercultural competence can refer to the ability to complete the effective and appropriate intercultural communication between communicators of different cultures. Although there is no consensus on the definition of intercultural communication competence up to now, scholars generally agree that the results of intercultural communication should be evaluated from aspects of effectiveness and appropriateness.

\subsection{Dimensions of Intercultural Competence}

To study dimensions of intercultural competence is a dynamic way to study intercultural competence. A number of scholars proposed a list of dimensions of intercultural competence. One of the most influential model of dimensions of intercultural competence was put forward by Byram (1997). He divided intercultural competence into four dimensions, namely, knowledge, skill, attitude and awareness. Deardorff (2004) also claimed that intercultural competence is based on individuals' intercultural knowledge, skills and attitudes. Hu Wenzhong (2013) considered that intercultural competence could be summarized as three parts, namely cognition, emotion (attitude) and behavior. Meanwhile, Yang Yang (2014) also pointed out that intercultural competence should be mainly categorized from the aspects of knowledge, attitude and ability, containing six modules: national cultural knowledge, foreign cultural knowledge, 
attitude, intercultural communication skills, intercultural cognitive skills and consciousness. The most recent empirical study on intercultural competence dimensions and assessment in China is the Fuzzy Comprehensive Evaluation Index System of Chinese College Students' Intercultural Competence (Fan et al., 2013). It is composed of six sub-dimensions: knowledge of self, knowledge of others, attitudes, intercultural communicative skills, intercultural cognitive skills and awareness. As a whole, dimensions of intercultural competence generally accepted by people include consciousness, attitude, knowledge and skills (Liu, 2015).

\section{Study Methods}

\subsection{Research Questions}

This paper mainly investigates the intercultural competence of Thai majors in the " $3+1$ " program in our institute. The main research questions are as follows:

1) Are there any differences between before overseas study and after overseas study in the overall score and six dimensions of intercultural competence? If yes, what are they?

2) If yes, why are there these differences?

\subsection{Subjects}

This study selected 85 Thai majors (grade 2016 and grade 2017) who studied abroad for one year in the " $3+1$ " program in our institute as the research subjects, including 16 male students and 69 female students.

\subsection{Investigation Instruments and Design}

This study adopted both intercultural competence assessment and interview to analyze the effect of the "overseas study" learning mode on cultivating and improving students' intercultural competence.

\section{- Intercultural competence assessment}

The self-assessment of intercultural competence was revised based on the Fuzzy Comprehensive Evaluation Index System of Chinese College Students' Intercultural competence which has high efficiency and reliability (Fan et al., 2013). The assessment mainly included two parts. The first part was personal information, and the second part contained six dimensions: native culture knowledge, Thai culture knowledge, attitudes, intercultural communicative skills, intercultural cognitive skills and awareness. The assessment adopted the format of five-point Likert scale, from 0 to 5 , on behalf of weak to strong.

\section{- Interview}

The qualitative study was carried out by means of the one-to-one half-structured interview. 10 stratified sampling students were invited to attend the interview based on their intercultural competence. Through interviews, this paper investigated the development and changes of Thai majors' intercultural competence in their overseas learning. Then, the factors that influenced the development of college students' intercultural competence were summarized. 


\subsection{Data Collection}

80 Thai majors were invited to finish the assessment which took them $10 \mathrm{mi}-$ nutes for the completion. The students' valid questionnaires were 50 and the valid percentage was $100 \% .10$ students attended the interview in time. Thus, the investigation was valid enough.

\section{Data Analysis and Discussion}

This part analyzes and compares Thai majors' intercultural competence before and after overseas learning from the dimensions of native culture knowledge, Thai culture knowledge, attitudes, intercultural communicative skills, intercultural cognitive skills and awareness based on the data from intercultural competence assessment scale and interviews.

\subsection{Comparison of Intercultural Competence}

\section{1) Comparison of general intercultural competence}

The intercultural competence assessment scores of the second-year group (before overseas learning) and fourth-year group (after overseas learning) respectively were contrasted in Figure 1 and Table 1. In addition to graphical contrast, Independent Samples T-Test was adopted to figure out whether there were significant differences between second-year and fourth-year undergraduate's intercultural competence average scores in statistics. From the data, the intercultural competence average of the "after overseas learning" was higher than that of the "before overseas learning", there was no significant difference on the whole. However, in the dimensions of native and Thai cultural knowledge, intercultural skills and awareness, there were discrepancies.

Table 1. IC assessment results contrast by overseas learning.

\begin{tabular}{ccccc}
\hline & Grade & N & Average & T-test (P) \\
\hline NC & before overseas learning & 85 & 3.73 & 0.000165816 \\
TC & after overseas learning & 85 & 3.31 & \\
& before overseas learning & 85 & 2.81 & 0.000000359 \\
AT & after overseas learning & 85 & 4.18 & \\
& before overseas learning & 85 & 4.03 & 0.575216149 \\
SK-1 & after overseas learning & 85 & 4.09 & 0.010366061 \\
& before overseas learning & 85 & 3.64 & \\
SK-2 & after overseas learning & 85 & 3.89 & 0.279562962 \\
& before overseas learning & 85 & 3.44 & \\
& after overseas learning & 85 & 3.58 & 0.242450621 \\
AW & before overseas learning & 85 & 3.85 & \\
& after overseas learning & 85 & 4.13 & 3.58 \\
\hline
\end{tabular}




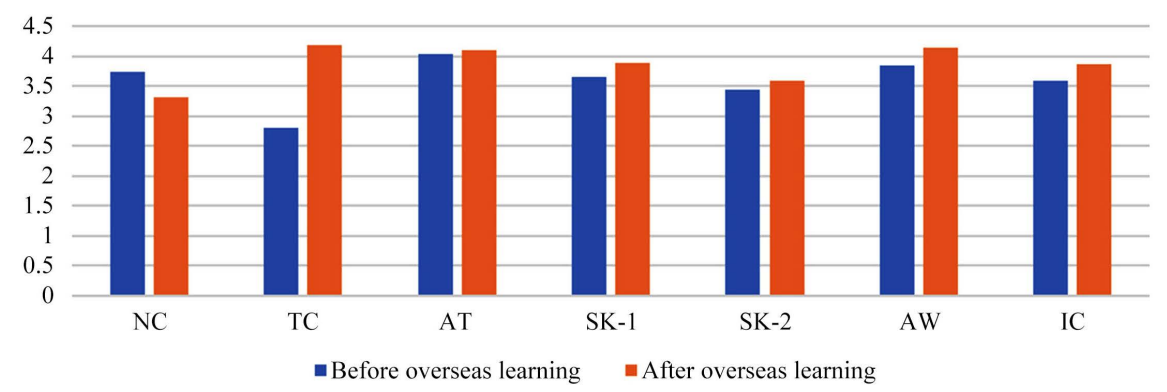

Figure 1. IC average contrast by overseas learning.

\section{2) Comparison of native and Thai cultural knowledge}

There were some differences by the overseas learning in cultural knowledge. In the aspect of native culture knowledge, students' average was not improved but declined a little from 3.73 to 3.31 and its p-value was less than 0.05 . This meant there existed discrepancy. Contacting to more target culture and less Chinese culture may lead to this result. The most significant difference between the two groups was recognized in the dimension Thai Culture knowledge, with a remarkable discrepancy from 2.81 to 4.18 as displayed in Table 5.1. This table also showed its p-value $<0.0001$. Namely, there were significant differences in knowledge of Thai culture. The level has been improved from low level to high level. The process of learning in Thailand made students contact and understand more target culture.

\section{3) Comparison of intercultural communicative skills}

The third discrepancy could be found in the fourth dimension SK-1, where the average of the "after overseas learning" fell at high level whereas the "before overseas learning” was merely at medium level. Its' p-value was less than 0.05 , which implied that there were differences between them. In Thailand, Thai language learners were intercultural people in the third space where two cultures (Chinese culture and target language culture) converge. This intercultural experience promoted them to grasp useful and helpful intercultural communicative skills.

\section{4) Comparison of intercultural awareness}

The last discrepancy could be found in the sixth dimension Awareness, where its p-value was also less than 0.05 . The overseas experience improved their intercultural consciousness and became much more sensitive to cultural difference.

With regard to the rest two dimensions, SK-2 and AT, no significant difference can be identified between the two groups.

The data in the figure and table was in accordance. The overall intercultural competence scores of two groups manifested significant differences. It was believed that the effectiveness of overseas learning in developing learners' intercultural competence was significant on the whole. Especially, there was strong degree of progress in knowledge related to Thai cultures and intercultural communication skills and awareness. 


\subsection{Factors Affecting the Changes of Intercultural Competence}

The purpose of the interview was to explore the factors affecting the ICC. Based on the scale, we designed interviews and interviewed 10 students. According to the interview data, some factors were summarized.

\section{1) Effect of gender on intercultural competence}

Both assessment and interview showed that girls were more nervous than boys when they encounter communication difficulties. Figure 2 explained the undulation of intercultural competence average score of male and female students. From Figure 2 the score of male students fluctuated between 3.90 and 4.36, but the score of female students fluctuated between 2.80 and 4.12. Male students' average of intercultural competence 4.11 was higher than female students' 3.59, especially in terms of knowledge, intercultural communication and cognitive skills and attitudes. Apart from the personal language ability, the overall performance of the males was better.

In the interview, we found that male Thai majors performed much better than the female. We learned that the male students interviewed had more intercultural communication experience than the female students. Males were more easygoing and open-minded in the new environment. They preferred to go out for communication and practice. At the same time, it was revealed that in the face of communication barriers, most of the males would use body languages to assist communication, while the females were usually in a hurry and don't know what to do. In conclusion, gender is a major factor affecting intercultural competence.

2) Effect of language and culture knowledge on intercultural competence

Among the students interviewed, including those who passed the Thai language proficiency test and those who failed. In the interview, 8 interviewees held the idea that language proficiency played the crucial role in their intercultural communication.

Language communicative ability included the necessary grammatical knowledge, the conceptual meaning of words (that is, the understanding and application ability of the original meaning and cultural connotation of words and metaphorical meaning, etc.; not only refers to the correctness of language, but also

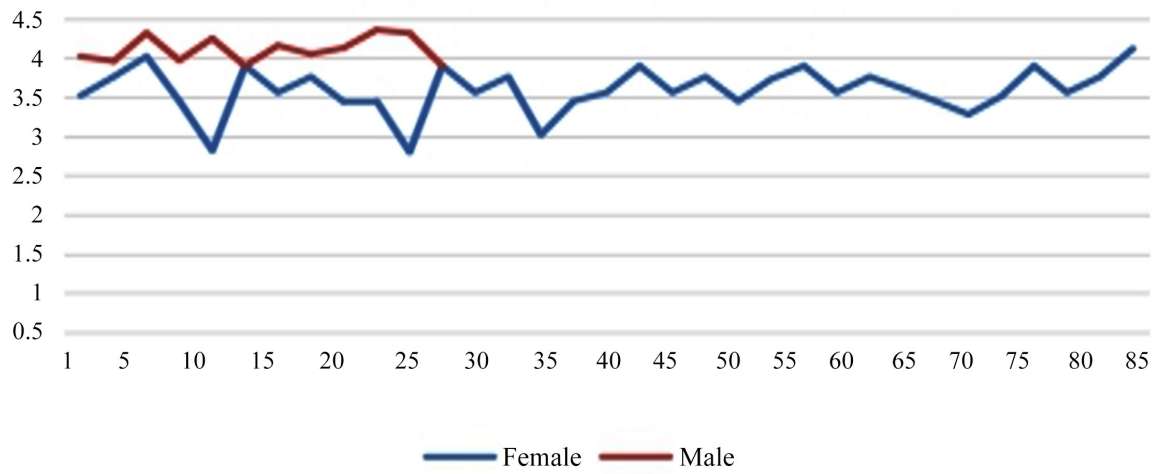

Figure 2. Comparison chart of average ICC of male students and female students. 
refers to the use of language in specific contexts, appropriateness in communication. Basic knowledge of language is a prerequisite for communication. Cultural knowledge and cultural adaptability are also important components of communication ability. According to the view of linguist Hymes, communication ability has several important parameters, namely grammar, appropriateness, and practicality. Grammar is more obvious in English teaching in China, and most students master it well; the essence of suitability and appropriateness refers to the social and cultural ability of language users, requiring language users not only follow certain grammatical rules, but also follow certain rules of communication, including all communicative behaviors including language communication, social norms, moral codes, other people's lifestyles and values, etc. When people communicate, a common phenomenon is to apply the behavioral norms of their own society to determine the reasonableness of the other party's behaviors. Due to the differences in the behavioral norms of the two parties, misunderstandings often arise. This is also a problem that we often overlook in traditional English teaching. It is a major obstacle to intercultural communication.

When talking about the intercultural knowledge module, six students mentioned that they were all deficient in Thai cultural knowledge. Therefore, when they talked with others, they would be nervous and afraid that they could not find something to talk about, which made them afraid to communicate with others. However, students who were familiar with Thai cultural knowledge and language said that they could always find the interesting topic in the conversation, and they could express their own opinions in the conversation and talk freely with others.

\section{Implication}

\subsection{Strengthen Culture Comparison}

For Thai majors, foreign language study not only focuses on target language and culture but also native language and culture. Intercultural is a double-way communication, it is also necessary to spread our Chinese culture to the worldwide. In the process of learning Thai culture, comparing and contrasting with Chinese culture is significant, which helps students have a cognitive awareness of cultural differences and similarities between the two cultures. Studying the difference between the cultures could probe the distinctive characteristics of the various cultures. In other words, it is quite necessary to contrast cultures in language teaching, for this would lead students to understand different cultures deeper and cultivate students' critical cultural awareness. Byram (1997) defined critical cultural awareness as the ability to evaluate critically on the basis of explicit criteria perspectives, practices and products in one's own and other cultures and countries. It involves both high sensitivity and cultural diversity and the ability to make an unbiased evaluation of both one's own and other cultural groups. Moreover, this develops a right attitude towards cultural difference and cultural diversity. On the one hand, learning native culture knowledge can develop the 
self-cultural awareness and will serve as the necessary supplement to foreign language learner's learning of their target language and the development of their competence with target culture. On the other hand, the process of target language learning and target cultural competence development will help language learners reflect and better understand their native culture, and also learn about their own identity. What's more, the self-awareness and reflection on one's native culture can help learners get rid of ethnocentrism and develop an open and tolerate value system.

\subsection{Strengthening Female's Mental Health Education}

Females are more sentimental than males in the new environment. Colleges may pay closer attention to female students abroad and carry out activities such as psychological consultation and mental health survey for them. It is suggested that they'd better communicate more with their family, friends and classmates, share their joys and sorrows to find emotional support. They are encouraged to be positive to solve the adaptive problems and overcome the adaptation barriers.

\section{Conclusion}

This study adopted both quantitative and qualitative methods to investigate the development and changes of Thai majors' intercultural competence in their overseas learning. In addition, the factors that influence the development of college students' intercultural competence are summarized. The study finds that there are differences in the dimensions of native and Thai cultural knowledge, intercultural skills and awareness. Gender, language capability and culture knowledge are responsible for the discrepancy. The paper proposes that it is inevitable to strengthen culture comparison in overseas learning and strengthen female's intercultural competence.

\section{Project}

1) Yunnan Agricultural University Social Science Young and Middle-aged Project: A Comparative Study on Intercultural Adaptation of Southeast Asian Language Majors during overseas study, Project number: 2017SK09.

2) Education Department of Yunnan Province Project: Study on the Influence of Overseas Study on Intercultural Communication Competence of Thai Majors, Project number: 2021J0103.

\section{Conflicts of Interest}

The author declares no conflicts of interest regarding the publication of this paper.

\section{References}

Byram, M. (1997). Teaching and Assessing Intercultural Communication Competence (pp. 70-73). New York: Muitilingual Mattera. 
Deardorff, D. K. (2004). The Identification and Assessment of Intercultural Competence as a Student Outcome of Internationalization at Institutions of Higher Education in the United States. North Carolina State University.

Fan, W. W., Wu, W. P., \& Peng, R. Z. (2013). F-Evaluation Analysis of Chinese College Students' Cross-Cultural Competence. Foreign Languages in China: Chinese and English Edition, 6, 53-59.

$\mathrm{Hu}, \mathrm{W}$. Z. (2013). How to Locate Cross-Cultural Communicative Competence in Foreign Language Teaching. Foreign Language World, 6, 2-8.

Kim, Y. Y. (1991). Intercultural Communication Competence: A Systems-Theoretic View (pp. 259-275). In S. Ting-Toomey \& R. Korzenny (Eds.), Cross-Cultural Interpersonal Communication. Newbury Park, CA: Sage.

Liu, X. (2015). An Analysis of the Elements of Cross-Cultural Communicative Competence. Cultural and Educational Data, 25, 178-179.

Lusting, M., \& Koester, J. (1996). Intercultural Competence: Intercultural Communication across Cultures. New York: Harper Collins College Publishers.

Samovar, L. A., Porter, R. E., \& McDaniel, E. R. (2010). Communication between Cultures (7th ed., p. 2). Boston: Wasworth.

Spitzberg, B. H. (2000). A Model of Intercultural Communication Competence. In Intercultural Communication: A Reader. Belmont: Wadsworth Publishing Company.

Wiseman, R. L. (2003). Intercultural Communication Competence. In W. B. Gudykunst (Ed.), Cross-Cultural and Intercultural Communication. London: Sage Publications.

Yang, Y. (2014). Research on the Constitution and Model of Cross-Cultural Communicative Competence. Journal of Tianjin Foreign Studies University, 4, 50-58. 